\title{
Creativity, organisation and entrepreneurship: power and play in the ecological press of money
}

\author{
Rolland Munro \\ University of Leicester
}

\begin{abstract}
Drawing on how Marx reverses consumption perspectives (C-M-C) to capture the money-orientation of entrepreneurs (M-C-M), the paper addresses ways the 'ecological press' of creativity (Rhodes, 1961) is affected by money-orientations becoming internalised deeply into institutions. Accepting Hjorth's (2005, p.389) critique that managerialism aims at producing 'today's ideal of self-managing enterprising employees', the pressing issue is to understand how organisation, when re-configured around budgets, targets and other metrics, can be opened up to passion, carnival and play without augmenting the 'power of place'. Asking how 'spaces of play' get foreclosed by the 'ecological press' of creativity being turned towards moneymaking, particular scrutiny is given to the ways in which 'institutional logics' (Thornton \& Occasio, 2008) get altered by internalising money-orientations. Three paradigm cases of innovation are examined: namely Edison's supply of electricity, Sloan's use of ROI to grant autonomy, and JIT's lead towards the flexible factory. While suggestive of the role money may play in limiting creativity to the possible and the potential, the analysis shows how change towards the virtual can be triggered by complex modes of reverse-thinking. While the analysis challenges 'market logics' that put creativity in the hands of the 'chance and caprice' of internal competition, I conclude that negative effects on the ecological press of creativity, such as 'making play pay', might be better countered by more research over how money's presence and absence is created and tempered.
\end{abstract}

Key words: Ecological press, innovation, institutional logics, metrics, moneyorientation (M-C-M), power of place, reverse-thinking, spaces of play, the virtual.

\section{Introduction}

While Benkler (2006) argues 'new logics', centred on openness, sharing, and external engagement, overcome 'institutional logics' (Thornton \& Ocasio, 1999) that cramp creativity with their cultural conformity in attitudes and beliefs, others focus on reconfiguring organisation to make it entrepreneurial. To date progress here falls well short of Hjort's (2014) call for organisation-creation around the formation of 'spaces of play' to inculcate passion and carnival. With play reduced to away-days and teambuilding exercises, reform of institutions relies on the metrics of money to 'reverse out' inward-looking tendencies and thus re-configure the institution's interiority into a site of competition. If the aim is to mirror neoliberal portraits of its exteriority, it is no 
surprise leaders end up re-structuring the institution into a conglomerate of disparate ventures - in line with Cantillon's mercantilism (Hjort, 2005:389) - each venture acting as the 'risk-taker' and with no single enterprise relied on as its mainstay for tomorrow.

In view of these diverse paths towards combining organisation with entrepreneurship, the paper addresses how increasing internalisations of money and its metrics affects the 'ecological press' of creativity (Rhodes, 1961, p.307). Money tends to be omitted from any analysis of creativity whenever it is seen as a source and expression of rationality, producing a levelling of feeling and attitude (Simmel, 1997) that appears inimical to the spirit of passion and carnival. When treated as an exogenous factor it is apprehended either as an inevitable constraint on the timing and process of innovation, or seen as a motive in the mind of the entrepreneur who spots an opportunity 'out there' to be exploited. While not discrediting stories of accidental entrepreneurs or home inventors working in garages (Peters \& Waterman, 1982), it seems vital to get more leverage on how the internalisation of the metrics of money alters the 'place' of organisation away from the stultifying effects of institutional logics; and, in so doing, opens up 'spaces of play' (Hjorth, 2005) for entrepreneurial activity.

Creativity, as this paper illustrates, involves, among other matters, reversethinking. As reverse-thinking ranges from simple inversion, as in brainstorming exercises, to the complexities of overthrowing institutional logics, it is vital to elaborate different ways of unlocking the grip of established practice. Specifically, Hjorth and Johannisson (2008, p.343) powerfully distinguish changes in practices as falling into three categories, 'the possible', 'the potential' and 'the virtual':

The vision, as Deleuze (1988) has pointed out, relates to its future practices like the virtual relates to the actual: by imagination. This is not the possible, i.e., one of the different form-content arrangements that could be made. Nor is it the potential, i.e., the tension between what our experiences of the concrete suggest as possibilities and the advent of the new (Massumi 2002). The virtual is instead the swarming of incipiencies or tendencies, the power to become.

In Deleuze's (1988) analysis of Henri Bergson's process theories, the virtual is abstract and relates to 'pure recollection' (p.55) which can be 'actualised' in the future, whereas contrastingly the possible is 'realised' (literally real-ized) as the thought whose form is 'already visible' in the image of the object; and if not actually perceived, is 'at least perceptible in principle' (p.41). As Deleuze (p.17) quotes 
Bergson: 'For the possible is only the real with the addition of an act of the mind that throws its image back into the past once it has been enacted'.

Picking up on Bergson's association of 'the possible' with the past and Deleuze's (1988, p.55) tying of 'the virtual' to the future, I think it is helpful, in terms of innovation, to draw Hjorth and Johannisson's typology together with Lefebvre's (1991) tripartite analysis of the production of space. Specifically, the envelope of the possible thus looks to be governed by institutional logics; namely innovation is limited to alternatives compatible with the 'natural space' of the past. The scope of change expands to the potential when reflecting on external influences; innovation that challenges the 'absolute space' of the present. Finally, the promise of the virtual is to break open institutional tendencies towards isomorphism (DiMaggio \& Powell, 1983 ) - through a thinking that is yet to come; namely the 'abstract space' of the future.

A first aim of the paper is to make explicit how innovation affecting the 'place' of organisation has gone hand in hand over the last century with intensifications in the ecological press of creativity arising from money-orientations. Turning any institution's interiority into a site of competition, as I go on to discuss, reflects how matters such as bidding for funds have become an integral part of the managers' role and, further, how much outcomes of their ventures are now judged in monetary terms. A second aim is to show how these intensifications reshape the ecological press towards money and so affect the timing and shape of the afore-mentioned 'spaces of play' in terms of the above tripartite typology. For example, whereas the internal metrics of money may restrict creativity to 'the potential' of the present, or keep it hidebound to 'the possible' of the past, successful change looks to involve refining arguments (often perversely) and finding allies (perhaps in places others never think of). To unlock 'the virtual', as I illustrate below, includes overcoming accounting conventions that limit the scope of creativity to 'the possible' and 'the potential'.

After a preliminary section to clarify Michel de Certeau's distinction between strategy and tactics and explain how this sets up key differences between 'place' and 'space', I make a return to Marx. A close reading helps first to recall Marx's (2008[1887] scepticism about a reliance on 'markets' and, second, to show how his 
reversal of a consumption view of markets (C-M-C) sets up the entrepreneurial orientation around money (M-C-M). Drawing on the above-mentioned typology of the possible, the potential and the virtual, I then analyse three epoch-making acts of reverse thinking. While each of these have helped to open up 'the virtual' for future change, my point is to suggest how follow-up innovations ambulate, back and forth, between reform of the isomorphism of 'place' and further expansion of 'spaces of play'.

\section{Place and space}

In contesting managerial versions of entrepreneurship, Hjorth (2005) draws on Michel de Certeau to distinguish strategy, which involves the calculation (or manipulation) of power relationships that becomes possible 'as soon as a subject with will and power.. can be isolated' (de Certeau, 1984, p.36) from tactics, which are determined by the absence of a proper locus and are therefore open to alterations in everyday conduct. Inasmuch as the subjects able to strategize, for de Certeau (in the footsteps of Foucault), include a business, an army, a city and a scientific institution, the sociology of institutions appears particularly pertinent with its theorising of institutions around the notion of power (Giddens, 1984).

In pointing to institutions being highly regulated, de Certeau relates this outcome to a perceived need for managers to preserve their will to power and specifies each as being a 'place':

It postulates a place that can be delimited as its own and serve as the base from which relations with an exteriority composed of targets or threats (customers, competitors, enemies, the country surrounding the city, objectives and objects of research, etc.) can be managed. As in management, every "strategic" rationalization seeks first of all to distinguish its "own" place, that is the place of its own power and will, from "environment". (de Certau, 1984, p.36)

This analysis over power is different from contingency theory's linking organisational 'fit' with environment but has some consonance with institutional logics, particularly in terms of strategy inoculating 'place' from its exteriority. As Thornton and Ocasio frame matters, institutional logics operate as:

[the] socially constructed, historical pattern of material practices, assumptions, values, beliefs, and rules by which individuals produce and reproduce their material subsistence, organize time and space, and provide meaning to their social reality. (1999, p.804) 
While this definition varies from de Certeau's, the link is reinforced by Hjorth when he notes how strategy institutes 'place' in terms of its creating a 'logic' $(2005, \mathrm{p} .392)$.

In contrast to the stability being wrought (deliberatively or otherwise) over 'place', de Certeau envisualises tactics emerging within the cracks that surveillance by the proprietary powers leaves open. These he calls 'spaces':

The space of a tactic is the space of the other. Thus it must play on and with a terrain imposed on it and organized by the law of a foreign power. . [Hence] What it wins it cannot keep. This nowhere gives a tactic mobility, to be sure, but a mobility that must accept the chance offerings of the moment (1984, pp.36-37) Here de Certeau draws attention to how 'tactics' create a counter-veiling kind of power, albeit one circumscribed by the terrain and the law superimposed upon it. In institutional parlance, tactics thus open up 'space' within the institution and create surprises for the 'place'. Critically, though, such gains from a deployment of tactical play can only be temporary. As de Certeau points out, what 'it wins it cannot keep'.

This hierarchy of place over space is key to de Certeau's focus on the limits of everyday tactics and is thus central to his understanding of the direction the tactics of everyday power may take. Specifically, in any 'place' - as is well-documented in classic studies such as Burawoy's (1979) production games of 'making out' and Roy's (1959) time out breaks like 'banana time' - play within 'spaces' tends to converge into them becoming sites of resistance. I read Hjorth (2005) to be exploring how resistance within 'spaces' can be re-directed towards more creative ends. His interest is with innovation that, in 'occupying the gaps or interstices of the strategic grid', can produce a difference; and, in following artists entering a company, his study reports employees setting up a radio station to enhance local communication. However, in picking up on ambiguities in the literature between work and play, Sørensen and Spoelstra (2012) argue that, while spaces of work can be turned into spaces of play, spaces of play have their own immanent logic. This, in their view, prevents any reverse inversion. As this logic would seem to limit the role of organisation in fostering creative collaboration, this leads me to think that, in order to square entrepreneurship within on-going realities, what is being called for seems more akin to a reversal in the hierarchy of 'place' over 'space'?

My argument is that a reverse thinking that could challenge managerial versions of organisation would need to explicate better how money affects the intricate interplay between 'spaces of play' and what may usefully be called the 'power 
of place'. Given top managers' concern to preserve power, if not also their vision of 'place', it is important not to overlook how they, at least in de Certeau's analysis, will guard against any 'surprise' or unpredictable event that can 'corrupt or pervert the strategy's system' (Colebrook, 1997, p.124). This is particularly important where a privileging of 'spaces of play' over the 'power of place' augurs the prospect of unleashing the swarm of 'the virtual'. I return to this theme of power and play towards the end of the paper after tracing key steps in reverse thinking that go towards freeing up 'the virtual' for organisation. Since each case illuminates intensifications towards an ecological press of money, I turn first to Marx for his insights on relations between money and exchange.

\section{Factory logic versus society: reversals in ordering the division of labour}

Neoliberal ideas look back to Adam Smith for their reification of 'the market' and his valorisation of this as efficient. In this light much is made of the need for institutions to disembed themselves of their institutional logics and conform instead to the socalled logic of the market. Nor are these ideas restricted to business. For example, Latimer and Munro (2015) point to how 'reform' over the last fifty years inculcates competition inside public institutions. This understanding of 'markets' as the engine of competition, however, is put under erasure by Marx's analysis of capital.

As Marx (2008) suggests, it is the same bourgeois mind that praises division of labour in the workshop and denounces with 'equal vigour every conscious attempt to socially control and regulate the process of production'. They are unable to see that 'anarchy in the social division of labour and despotism in that of the workshop are mutual conditions' (Marx, 2008, p.220). Indeed, for Marx, justifying despotism in the factory - on the basis that this is the motor for increasing the wealth of nations - entails apologists for the division of labour in the factory occluding the daily havoc and disorder brought about concomitantly by the division of labour in society.

Taking the specific argument in Capital in reverse order, Marx points out that the tyranny that reigns in the factory, in which the mind and body of the workers are all too often crippled, is bought at the price of the owners of capital subjugating themselves solely to the coercion exerted by so-called market forces: 
Division of labour within the workshop implies the undisputed authority of the capitalist over men, that are but parts of a mechanism that belong to him. The division of labour within society brings into contact independent commodityproducers, who acknowledge no other authority but that of competition, of the coercion exerted by the pressure of their mutual interests (Marx, 2008, p.219). Whereas in the workshop 'the iron law of proportionality subjects definite numbers of men to definite functions', in the society outside the workshop 'chance and caprice have full play' - specifically in distributing the producers and means of production among the various branches of industry (p.219).

Marx's insight here is that this state of affairs is subject to a further inversion in logic. Rather than consider what is good for society being imposed upon the factory, the implication is that this priority gets reversed in neo-liberal thinking:

The $a$ priori system on which the division of labour, within the workshop, is regularly carried out, becomes in the division of labour within the society an $a$ posteriori, nature-imposed necessity, controlling the lawless caprice of the producers, and perceptible in the barometrical fluctuations of market prices (Marx, 2008, p.219).

Morality and history are put into reverse. Evolution economists nowadays treat man's (sic) earliest nature, not as social and cooperative, but as intrinsically competitive. So much so that they see organisation - such as the factory - as taming and harnessing this raw energy. Competition, once it is disseminated as the only acceptable way to order society, brings about a Weberian reversal in the order of things: namely for a democratic state to gain the desired 'end' of competition, the 'means' of tyranny is justified.

Although he does not spell this out, it seems permissible to infer that Marx views money, not the market, as the primary linking mechanism in a capitalist society. Certainly much writing in Capital is aimed at understanding how money works and in the next section I suggest how Marx's analysis of money in terms of a circulation of capital challenges the idea of 'market logic' and, critically, reverses out traditional ways of relating money to production.

\section{Process: circulating the money}

Part I of Capital is headed up 'Commodities and Money'. As is well established Marx begins Chapter 1 with the use value of a commodity, but rapidly moves on through the notion of exchange value to note the 'dazzle' of its money form. The riddle for Marx, who perceives value can only 'manifest itself in the social relation of 
commodity to commodity' is how use value becomes 'hidden' behind its 'dazzling money-form' (Marx, 2008, p.23).

In Chapter 3, Marx goes some way to solving this riddle by addressing the 'metamorphosis of commodities'. This stage in his analysis tracks exchange as a process by which commodities leave the hands in which they are non-use values into hands where they become use values. As he notes this is 'a social circulation of matter' (p.64). However when he accompanies the owner of some commodity like linen to an actual (non-reified) market - 'the scene of action' (p.65) - he sees the linen exchanged for gold. He further observes how the gold that has replaced the 'alienated' commodity is now exchanged for a bible. Marx represents this exchange process in the following way:

$$
\begin{gathered}
\text { Commodity - Money - Commodity } \\
\text { C-M-C }
\end{gathered}
$$

What Marx is observing is the way in which the presence of money drives out exchange in the form of barter. However, as Marx goes on to note, something else happens when commodities get into circulation through their money form:

Circulation bursts through all restrictions as to time, place, and individuals, imposed by direct barter, and this it effects by splitting up, into the antithesis of a sale and a purchase .. (Marx, 2008, p.73)

While Graeber (2011) has recently questioned whether barter ever existed as a system of exchange, some distinction needs to be made between systemic systems systems like money that are 'self-constructing' - and systematic systems - built operations that are 'designed' (Munro, 2016). In treating barter as a matter of convention, it is clear that Marx is treating money as more systemic and he goes on to underline how 'the one-sided character of the money's motion arises out of the two-sided character of the commodity's motion' - a circumstance that he notes is 'veiled over' (Marx, 2008, p.74).

In Part II of Capital, 'The Transformation of Money into Capital', Marx brings these matters to a head. To find the general form of capital, he inverts the previous formulation C-M-C to establish a new sequence:

$$
\begin{gathered}
\text { Money - Commodity - Money } \\
\text { M-C-M }
\end{gathered}
$$

In its reversal of the originating formula ( $\mathrm{C}-\mathrm{M}-\mathrm{C}), \mathrm{M}-\mathrm{C}-\mathrm{M}$ covers 'the transformation of money into commodities and the change of commodities back again into money' (p.93). Whereas before Marx had considered value only in terms of those who were 
the 'owners of commodities' (p.69), now he has arrived at a formulation that addresses circulation from the perspective of a capitalist.

Yet Marx does not rest there. Whereas C-M-C makes perfect sense as an initial ordering of exchange, what he points out is that its reversal, $\mathrm{M}-\mathrm{C}-\mathrm{M}$, is 'absurd and without meaning' (p.94). Without meaning, that is, if the result of the latter is not to increase the sum of money through circulation. Noting that in M-C-M money is not 'spent' but becomes an 'advance', he traces what he calls the 'reflux' of money - the way in which it is only put into circulation in order to be spat out again:

The character and tendency of the process $\mathrm{M}-\mathrm{C}-\mathrm{M}$, is therefore not due to any qualitative difference between its extremes, being both money, but solely to their quantitative difference. More money is withdrawn from circulation from the finish than was thrown into it at the start (Marx, 2008, p.96).

Unlike C-M-C, where exchange is kept within bounds by the 'very object it aims at, namely consumption, the circulation notated by M-C-M knows no bounds. It shifts the locus of exchange from 'the possible', or even 'the potential' for those who delay, into a world of 'the virtual' wherein opportunities for exchange have no logic other than to increase the quantity of money to be re-appropriated.

As Marx goes on to note: the circulation of money as capital is 'an end in itself' (p.98). Indeed, Marx indicates money has an 'automatic expansion' (p.98) that turns the world upside down. In showing how money becomes automatic in its circulation, Marx hints at its autopoietic tendency and so avoids the reification of 'the market' so prevalent in neo-liberal thought. So, rather than markets coming first, with money coming second, merely as a facilitator of exchange, money starts to come first. Hence, far from being the pre-eminent mechanism valorised by the neo-liberals, markets are thus needed primarily as a place for money to multiply itself within.

\section{The product: identifying the invention last}

Ever since electricity lit up our lives, associations of the light bulb with creativity became the stuff of comic book legend. Yet as his notebooks make clear, Edison's route to supplying electricity was far from a 'light bulb moment'. Indeed, his process for thinking through how to supply electricity in ways to compete with gas is a) unexpected in its identifying the necessary product last, b) complex in its twists and turns in the logic, and c) prolonged in him having to commission a search for the missing piece in his project. 
Opening up 'the virtual' - and harnessing electricity is surely a paradigm case of this - seldom comes from the inscrutable products of sporadic genius. Added to 'abundant and clear causes in prior scientific and technological development', they likely have:

.. social causes and retarding factors, both new and constant, of changed needs and opportunities, growth of technical education, of buying power, of capital, patent and commercial systems, corporation laboratories and what not.

(Gilfillan, quoted by Rhodes, 1961, p.309).

Certainly the light bulb fits Liphshitz's (1935) study of the history of inventions, which stresses they originate in a response to social needs and that there must be a sufficiently advanced stage of culture and a proper technical heritage to foster or allow an invention to be made.

Emphasising Edison's strategy is to replace gas with a supply of electricity, Latour (1987, pp.239-240) draws comprehensively on Edison's notebooks to detail the sequence he adduces to Edison. However, where Latour stresses heterogeneity in Edison's materials, my point is to identify the specific reversals in logic taken by Edison. Hence, while sticking to Latour's text, I enumerate each step in the creative process to underline its different twists and turns.

1 In 1878 Edison makes an accounting calculation of the project to deliver a complete system

2 The calculation includes price of steam engines, dynamos, engineers, insurance, copper etc

3 The results of the calculation adduce that the most expensive item in the proposed system is copper.

The first point is that Edison reverses the traditional sequence of innovation by beginning his creative process, not with an invention or an original product, but with an accounting calculation for the delivery of a complete system of electricity. As his notebooks make clear, Edison knows supplying electricity is a non-starter unless his system is as cheap as gas.

His accounting calculation first reveals - if he is to meet the market constraint on consumer price - copper as the critical ingredient. While Steps 1-3 look like the accounting exercise any business pragmatist would carry out today, this normalisation of procedure reflects Marx's reversal of C-M-C to M-C-M and his identification of the 'automatic' nature of money circulating from a perceived need to increase M-out over M-in.

While entrepreneurs are looking to get more M-out than they put in, Edison can't change the price of copper. So the next stage is to see how to reduce the quantity of copper needed:

4 The market constraint is the consumer price has to equal or be lower than the price of gas. It can't be more \& Edison can't change the price of copper. 
5 Joule's law implies more cross-section (thicker copper wire) reduces loss in distribution.

6 If can decrease current, then decrease size of wire = less copper.

His enemy here is Joule's law, since this tells him to use thick copper wire to avoid loss in distribution. However, by reversing this logic, Edison turns Joule's law into a potential ally as the reversal implies he uses less copper to supply electricity if he decreases the size of the wire used. This step still implies loss in distribution, but looks good inasmuch as less copper identified above as the vital ingredient - is needed.

Unfortunately, the step to use thinner wire also decreases the electric current and so now a different law stands in his way. Ohm's law informs Edison that the consequence of decreasing current is to increase resistance.

7 By Ohm's law [Resistance $=$ Voltage $/$ Current $]$, a decrease in current increases resistance

8 So decreasing current would mean increasing resistance of the lamp filament The issue now facing Edison is that decreases in current from thinner copper will increase the resistance of the filament in the lamp. Since this path burns out the filament too quickly, this forms a stop on the idea of thinner wire.

Yet avoiding the no-go area of burning out lamps is exactly what predicated others in this nascent industry towards low-resistance lamps. So if Edison is to turn the enemy of Ohm's law into an ally, he must reverse conventional lines of reasoning. Only then can he continue with the idea of thinner copper wire.

9 Everyone is looking for a low-resistance lamp to ensure filament won't burn out.

10 BUT the network of potential allies Edison has entangled himself in is absolute

11 Must find a high-resistance filament - since it is the only way to keep his other allies in place

12 Edison sends out human allies on a year long search for one that won't burn out (Latour, 1987, pp.239-240)

Taken together, Edison's inversions in steps $9-12$ help him to reverse himself out of the institutional logic that holds his rivals captive. Namely he can now escape the fixation that decrees bulbs - to avoid these being burnt out - must have a filament with low resistance.

What is critical about Steps $5-8$ coming after Steps 1-4 is to see first how the laws of physics are brought in by Edison after his calculations about money. In the heterogeneity of Edison's inscriptions, the laws of physics are made subservient to the rules of accounting. This looks odd in the face of the traditional representations of scientific discovery but looks, as discussed in the preceding section, entirely consistent with the M-C-M orientation noted by Marx. 
In addition to also demonstrating the interweaving of process and product constraints noted by Rosso (2014), what is evident in Latour's interpretation of the sequence Edison recorded in his notebooks is how the ecological press of money helps precipitate a set of crucial reversals in Edison's thinking. As vital, however, we can see how Edison's creative act arises out of his combining two further acts of reverse thinking. Inside step 6, Joule's Law is reversed first to show that a decrease in current reduces the size of wire needed - which means less copper is needed. Then in steps 7 and 8, Ohm's law is applied to infer how this necessary decrease in current will require a much higher resistance in the lamp filament.

What is of importance in all this is not only to point to how this initial search for materials to conduct electricity has opened up 'the virtual' to the multiplicity of electrical devices like telephones and computers as well as subsequent advances in miniaturisation from valves to transistors to silicon chips. As saliently, it is to put a reserve on the idea that institutional logics can be easily 'reversed out'. To the contrary, as Derrida (1981, p.135) suggests, mere inversion of prior formulations simply land one on 'older ground'. What is clear is that Edison drew on a set of reversals that - only in combination - let him to escape the functional fixation noted in early experiments on problem-solving. Rather than simple inversions being enough to open up 'the virtual', the above analysis illustrates how a sustained combination of reversals is necessary in order to proceed towards a novel solution.

\section{The Person: creating the modern manager}

In inspiring some of American capitalism's greatest achievements, Alfred Sloan's style of management evolved from organisational changes he wrought in General Motors over the years around 1920-23. As is well established these innovations formed a paradigm for later industrial firms (Micklethwait \& Wooldridge, 1996). Indeed, as Roberts (2004, p.2) argues, in its impact on people's lives as well as business enterprise, the multidivisional configuration stands out as one of the most prominent shifts of the twentieth century. Yet for all this emphasis on the novelty of his divisional structure, what I wish to argue is that Sloan's more lasting legacy is to bring money and management together inside institutions in ways that today seem irreversible and irrevocable.

What is of interest is the complexity in these reversals in thinking. While not without critics - for example O'Toole (1995) argues Sloan's focus on organisation structure was detrimental to personnel considerations - the divisional structure not 
only reversed Henry Ford's valorisation of scale, but facilitated a decentralisation in decision-making as well as a 'repositioning strategy' over marketing (Powers \& Steward, 2010). In all this, however, the common portrayal of Sloan as inventing decentralisation misleads. Governments, in evolving administrative practices, had long devolved authorities to generals leading armies and put potentiates in charge of the good running of a colony. Nor was administrative theory, with its emphasis on top-down instruction, yet destined for the dustbin of history - to borrow Kuhn's (1970) famous phrase.

As Sloan (1967) details in Chapter 2 of My Years with General Motors, the setup was unlike Ford, since General Motors was effectively a conglomerate of different companies, each with their different champions and styles. In noting difficulties in controlling these Divisional barons, Sloan quotes from a study he made well before the reorganisation in $1920-21$ as follows:

The approval of any member of the Executive committee of an Appropriation Request [allocation of money] by a Division over which he had supervision, necessarily carried with it the support of other members of the Executive committee. In other words, from the practical standpoint, the supervision supposed to be exercised by the Executive Committee was more theoretical than practical. (Sloan, 1967, p.53)

Decentralisation, to Sloan's consternation, was already, if tacitly, effectively in place!

Indeed, the emphasis on decentralisation hides key details in the novel nature of Sloan's reverse-thinking. The reversal Sloan brought about was neither to give independence to the Divisions, nor counter their autonomy. Critically, his awareness extended to the dangers of operational decisions being taken at corporate level. Far from advocating power being exercised from either the top or below, he took the view that control had to be exercised both ways. This led to the 'contradictory nature' of his twin principles, noted with amusement by Sloan on re-reading what he wrote in his 'Organisation Study' of 1919 (p.76), where he asserts that the second objective - centralisation from 'looking from top down' - was 'a restatement of the first point, but in reverse' (p.79, emphasis added).

Yet, despite this reorganisation being officially adopted as 'basic corporation policy' (p.77), and a 'best-seller' within General Motors, the new policy failed to translate into realities over the next two years and even 'violated' its first principles (p.94). What brought matters to a head forms one of the longest chapters in Sloan's book (pp.94-118). This painful episode involved the new Board under Pierre du Pont 
championing a copper-cooled engine - invented its head of research. This top-down support continued - despite teething problems within the Divisions - until an upsurge in sales dictated its abandonment.

While problems with an unproven technology left Sloan sympathetic to divisional complaints about having manufacturing decisions foisted upon them, what finally broke the mould of a command structure was Sloan's determination to see division managers held responsible and accountable for their decisions. This innovative shift towards an embryonic control structure - which Chandler (1962, 1977) identifies as the crucial change - was made possible however only by a new technology called return on investment (ROI) - its innovator, Donaldson Brown, being fortuitously imported alongside Pierre du Pont from the chemical giant.

On 'the influence of rate of return on decentalization' Sloan made the following twin notes at the time:

.. [ROI] increases the morale of the organization by placing each operation on its own foundation, making it feel that it is part of the Corporation, assuming its own responsibility and contributing its share to the final result.

.. [ROI] develops statistics correctly reflecting the net return and the invested capital of each operating division - the true measure of efficiency - irrespective of the number of other divisions contributing thereto and the capital employed within such divisions (p.75).

In linking ROI to the money-orientation of entrepreneurs (M-C-M), Sloan's seminal insight was to see, against existing institutional logics, that division managers had to have the power to refuse any new innovation - even those invented 'in-house'. His novel contribution was to reverse extant policy and, instead, insist on Research and Development having to 'sell' any innovation to the Divisions. His thinking was that only when division managers voluntarily took innovation on board could they be held responsible for any subsequent increase or decline in profits (see also Anthony, Dearden \& Vancil, 1965).

Was Sloan a genius? I don't think so. This is not only to note the allies he enjoyed, like du Pont, and the luck of gaining a genuine innovator in Donaldson Brown. Much of the story of the copper-cooled engine reflects Sloan's passion for 'due process' - the cumbersome bureaucratic procedures concomitant with administrative protocol. More critically, the changes he wrought are in line with Marx's insights over M-C-M, namely in its entrepreneurial perspective demanding more $\mathrm{M}$ to be spat out than put in. For all Sloan accepted executive power over 
subsequent years, his outlook was from the first that of a 'money man'. While rising quickly in terms of management, his early inheritance facilitated a considerable investment in the ownership in General Motors. This entrepreneurial background oriented Sloan to want to compare the return on investment from different divisions.

So even if Sloan is not the patron saint of modern management, he took the first steps that made money more present within the institution. By pressing ROI into Division level, instead of leaving it at the corporate level, Sloan imposed an M-C$\mathrm{M}$ formulation on those below. In aiming to join accountability with responsibility, he created the door for others to install further money-orientations and, critically, drill its metrics down the hierarchy through the practice of budgeting. This opened up 'the potential' for Division managers go outside the 'natural space' of institutional logics, discussed earlier, and act entrepreneurially (i.e. able to respond to the influence of external change). Indeed, it would also not be long before 'the virtual' would set organisation on its long path of creating the modern manager at much lower levels than he likely envisioned. In the swarming of its 'incipiencies or tendencies', including budget games (Hofstede, 1968) and short-termism, the subsequent unfolding of this virtual space had the affect of subjecting even low-level managers deep into the ecological press of money.

\section{The place: rethinking the factory}

Any entrepreneurial creativity arising from the M-C-M orientation being drilled down an institution was soon circumscribed by budget games and short-termism becoming part of the 'tactics' deployed by managers. Indeed, entrepreneurial flair was not something sought from production managers since the place of the factory was determined less by technological innovation and more by a strategic reliance on standard costing. Investment, including factory layout and machines purchase, was subject to an accounting calculation that placed fixed cost calculations (including recovery of investment monies by a 'depreciation' of capital costs) as the numerator over a 'standard volume' in the denominator, pre-set to represent ideal production runs. In this formulation, the longer the run, the lower went the notional unit cost.

Many ramifications flowed from the factory being ruled by this grip on investment by standard costing. In a society where scale appeared vital, there seemed little alternative to mass production. The consumer faced a world in which 
the affordable product was not only 'bog standard', it was likely of poor quality. Quality suffered because the logic of driving down standard cost directed innovation towards 'built-in obsolescence', for example by substituting materials at evercheaper prices. Additionally, with stopping long production runs incurring extra costs, factories relied on pre-production inspection to eliminate defective material and post-production inspection to identify sub-standard products. Consequently, either malfunctioning products were sold onto the customer, or inspection costs were pushed high with imperfect and sub-standard products jettisoned.

While garages and repair shops multiplied alongside this 'throwaway' society (Watkins, 1993) - a society which saw its workers as disposable as its goods immediate problems arose over inventory. To make the best of set-up costs and ensure uninterrupted production runs, institutional logics dictated companies invest heavily in inventory for raw materials and semi-finished goods. This was compounded by investment in finished goods to avoid customers waiting on future batches in the factory schedule. These institutional logics were reinforced in a selffulfilling manner by the business cycle, wherein any upturn in the economy led to an upsurge in demand for inventory and so justified building up inventory ahead of the next upturn.

An initial reversal in this hold standard costing had on investment arrived in form of Just-In-Time manufacturing (JIT). While initially seen as a whacky inversion (popularised in a fashionable movement termed 'Japanisation'), JIT subsequently opened up a 'virtual space' that included sustained campaigns that would change the face of the factory. This long overdue reversal in institutional logics was epitomised by a new emphasis on 'clearing the factory floor' (Munro, 1987). Storing 'heaps' of inventory had crowded out the factory, entailing larger-than-needed buildings and added expense in lost and damaged inventory. As Alles, Amershi, Datar and Sarkar (2000) argue, these incentives (which included significant beneficial effects on information quality) provided an economic rationale for modern manufacturing control practices such as JIT and zero-defect policies.

Additionally, proponents of JIT argued against the ubiquitous practice of expediting items in production. Whenever sales had the say over which order was more vital than another - as they increasingly did with adopting Sloan-influenced matrix structures - the long scheduled runs were interrupted in favour of producing 
a different line of goods! The inevitable outcome went beyond expediting causing self-defeating rises in costs as production runs grew shorter: frequent interruptions in the schedule from growing armies of expediters, each vying with the other, also incurred additional set-up costs. In time, experiments with JIT raised standards sufficiently to make quality a brand issue as much as price, and removed, as Klein (1990) details, much of the perceived need for expediting.

A new strategy for the 'place' of the factory - characterised later as 'lean manufacturing' by Womack, Jones and Roos (1990) - thus emerged around moving, whenever possible, either towards a 'produce-to-order' policy that made inventory in finished goods redundant or by cutting down on production uncertainties and simulating Toyota's manufacturing (Goddard, 1986). Specifically, in place of restricting machinery to 'the possible' of large-scale production, innovation drew on 'the potential' of smaller, adaptable, less-specialist machines. This not only facilitated multiple production lines that both enabled speed of response to new orders and reduced changes in set-up. Even more vitally, additional reversals in thinking opened up a multiplicity of paths towards agile manufacturing and so accelerated innovation towards 'the virtual' of the flexible factory.

The concept of the flexible factory is nowadays so commonplace, backed up by a myriad of innovations developed around bespoke manufacturing, that it is hard to comprehend just how much fabric of the industrial world was once shaped in the light of a single calculation tool for making money. Looking back at the global experiments with JIT in the 1980s, it is clear the dictator of the factory was not so much Marx's figure of the tyrannical owner as it was the prevailing notion of standard cost. For it was not only the spectre of competition that drove capitalists to build their factory around long production runs - their conviction about scale was spirited onwards by accountant's calculations. These evidenced, unshakably and apparently unequivocally, that production runs had to be as long as possible in order to drive standard costs down. The effect was to create an operating table (Gutting, 1989) that created intense pressure on the factory manager to work within the institutional logics of long production runs. Requests for smaller machines, or suggestions about 'the potential' of a flexible layout, would simply fall off this operating table. Even space for 'the possible', such as two machines instead of one, 
could fail to get started: the standard cost version of M-C-M would demonstrate two machines entailed shorter runs and thus prove them to be too expensive.

It is surely surprising that the rule of standard costing lasted for much of the $20^{\text {th }}$ century and that it was only towards its fourth quarter that 'the potential' for creativity in the factory crossed over into 'the virtual'. Prior to the challenge of JIT, with its across-the-board reversal of institutional logics (Voss \& Clutterbuck, 1989), there was however little to challenge the 'ecological press' set up around standard costing. Hence while some innovation aimed at reducing set-up costs, a true reversal in this dominance had to await the belated switch towards estimating the 'true cost' for each item. Until alternative costing systems arrived in the 1980s, including 'throughput cost', 'backflushing' (Munro, 1987) and 'activity based costing' (Kaplan \& Cooper, 1988), few had thought of adding up inventory costs onto unplanned setup costs, or multiple inspection and reject costs, or factored in the costs incurred in 'expediting'.

Effectively the production myopia around standard cost had been driving the un-thought-through strategy of 'make and sell'. Arguably investment in the 'place' of production unwittingly mimicked the C-M-C orientation of Marx's lone producer; and so deepened the divide that kept production apart from sales. Indeed, it may have incarcerated larger companies in institutional logics that led them to invest heavily in their sales and marketing infrastructure. Certainly innovation here responded down the road of 'the possible' (for example, refining methods of discounting to unload unwanted stock) and 'the potential' (innovating techniques for pressure sales with devices to reward the most shameless in a bonus culture).

While JIT was dubbed initially with some justice as more myth than fact, an in-depth analysis of the voluminous literature on JIT by Mackelprang and Nair (2010) suggests a positive relationship between JIT manufacturing practices and aggregate performance. Arguably, however, reorientation towards JIT was always more about the creativity of its ideas (Dear, 1988). This is because the 'abstract' nature of 'the virtual' is always pointing to the 'swarming' of changes that may happen in the future. As Massumi (1998, p.16) points out if the virtual is change as such, then in any actually given circumstances, it can only figure as a mode of abstraction'. So too, just as there is no author to whom 'the virtual' is attributable (Massumi, 1998), it is foolhardy to attribute to JIT all the changes that followed its 
initial reversals. While emphasising the deformation of institutional logics that embalmed the factory in large-scale production, any deep analysis over the complex reverse thinking epitomised by JIT should not overlook the extent to which other challenges were waiting in the wings and could be drawn into the wider debate about redesigning the factory. In addition to finding ways to measure throughput costs, 'allies' had to be found in order to help create 'the virtual'. For example, as Hall (1987) illustrates, radical thinking from Deming (1966) was pulled in to show quality need not be expensive.

What is to be borne in mind nonetheless is that while ideas associated with JIT moved Western companies away from the push production that dominated threequarters of the $20^{\text {th }}$ Century, this has not improved the lot of those working in the factory. It is also the case that a) replacements to the unwitting C-M-C orientation imposed by standard costing has intensified an M-C-M orientation and b) follow up changes to practice have taken flexible production and outsourcing much further. Indeed, in another Weberian reversal in the order of things, institutional values like honesty and selflessness have been sacrificed in order to attain an ever-greater intensification of the ecological press of money: once again the 'end' of competition appears to justify the 'means' of tyranny.

\section{Creating spaces of play: money and its extensions in time and space}

The paradigm cases of reverse-thinking analysed in this paper highlight first a dominant process in how Marx in Capital reverses the traditional logic of exchange to uncover the perspective of the capitalist and entrepreneur in their search for ways to turn money into more money. To illustrate this, I detailed complexities in reversethinking that turned Edison's constraint of supplying electricity for the same money as gas into a search for a product with a high resistance element. I then recounted the long and difficult years during which Sloan reversed the top-down reliance on 'command' with a template of 'control' that imposed divisional accountabilities on persons: thus inculcating a money orientation (M-C-M) internally by comparing the rate of return of money across different ventures. Finally I returned to the place of the factory to inspect how 'the potential' from Just-In-Time's reverse-thinking swarmed into 'the virtual', creating a revolution in manufacturing which, along with 
arguments over quality and agility, overthrew institutional logics built around largescale machines and long production runs.

Caught up in management rhetoric of about 'going forward', it is easy to forget how progress in any field is as much a process of reversals as it is of advances. Whereas Hegelian dialectics emphasises a continuous shifting back and forth between thesis and antithesis, management theorists tend to present developments in organisation somewhat seamlessly. Such commentary does more than obscure a rich diversity in substance and style; its linear narrative of progress also hides the convoluted nature of the most important creative leaps. As Clegg (1981) argues, new administrative systems are built on, and exist alongside, the old systems. The fact is researchers are likely to find multiple layers of managerial technologies co-existing in the 'place' they study (Munro, 1995), each dating from a certain historical era.

For these reasons Chandler (1977) may be mistaken in arguing management acts alone as the 'visible hand'. In the kind of control-centric corporation Sloan ran, it is not markets, but primarily money which was brought very visibly 'inside' General Motors - namely by performance being made subject to measures of return on investment (ROI). Since then, the potential for entrepreneurial activity is enlarged by budgets and other monetary forms being drilled down to lower levels. This on-going process no doubt reflects beliefs in the money economy generating a concern for precision and punctuality (Simmel, 1997) more than its ability to inspire creativity through management being freed up from a 'command' structure. So far the result, as noted above, is often short-termism and 'budget games'. Yet with senior managers seemingly ready to abandon the task of co-ordination, this internalisation of money appears to open up 'the virtual' in ways whereby it is money, not the market, which now directs operational work in corporations.

In depicting how this internalisation of money turns arguments over structure upside down, creating the potential for 'spaces of play' to accommodate entrepreneurship, my emphasis remains far from suggesting top managers relinquish power. No simple inversion is possible and 'place', in de Certeau's terms, remains firmly in place. Indeed, to the contrary, executive power is much enhanced by the senior manager's grip on the ecological press of money. So much so that it is vital to explain how those given oversight appear to remove themselves from the creativity process but nonetheless are never entirely absent. Hence, when managers 
create conditions for play that have 'desirable effects for organizations and their members', such spaces, as Sørensen and Spoelstra (2012, p.95) imply, can easily be usurped. And no more so than when the internal metrics of money is tied back to the M-C-M logic of global money markets; it is the 'time-space compression' of the latter (Harvey, 1989) that tends to dictate the speed in which 'money in' has to be multiplied as 'money out'.

In exploring this perplexing issue of how the use of money for managing and co-ordination can then be turned into an incipient 'space of play', I draw on Canetti's analysis, as Malabou (2015) does, for the difference between force and power:

The cat uses force to catch the mouse, to seize it, hold it in its claws and ultimately kill it. But while it is playing with it another factor is present. It lets it go, allows it to run about a little and even turn its back; and, during this time, the mouse is no longer subjugated to force. But it is still within the power of the cat and can be caught again. . The space which the cat dominates, the moments of hope it allows the mouse, while continuing however to watch it closely all the time and never relaxing its interest and intention to destroy it - all this together, space, hope, watchfulness and destructive intent, can be called the actual body of power, or, more simply, power itself. (Canetti, 1973, p.281, emphasis added)

As Canetti goes on to say, inherent in power, as opposed to force, is an extension in time and space; and to be sure these kinds of 'spaces of play' result in quite different institutional mores from the 'iron cage' Weber foresaw.

The sheer conformity in conduct anticipated from institutional logics reigning supreme has given way, through the introduction of budgets and monetary targets, to a 'flexi-cage' that expands and retracts at a senior manager's discretion. At one moment the 'time-space compression' is relaxed, with operating managers given room for manoeuvre in how and what they spend. In the next, the M-C-M orientation is intensified as more senior managers exercise their discretion over how and when to tighten their claws. I think this explains, as much as anything, why senior managers are happy to let money inseminate itself inside the corporation as an 'ecological press'; and why less senior managers and their teams of employees are more and more challenged to come up with creative solutions.

It follows therefore that the use of money within institutions is not to be presumed to be limited to its direct affect on bodies and sensibilities. Rather its deployment arises as much from how money acts instead as a deferral on the use of 
force and opens up, instead, spaces in which to exercise power (Munro, 2001). Such discretion works for many because, as Giddens (1968) notes, power is best when 'running silently'. Hence when senior managers see little need to demean themselves by making interventions, all is well; they can choose to defer the use of force and so retain a useful ambiguity over the nature of power (see also Stinchcombe, 2002). Yet if circumstances arise where they feel a need to apply force they can (unlike the cat who needs no legitimation) justify 'usurping' the space of play by using the metrics of money to reveal how the mouse-persons brought calamity upon themselves.

In offering extension in terms of time and space, money can help to create a wide range of 'serious' spaces of play (Schrage, 2000). But, perhaps inevitably, many of these are caught within the time-space compression of M-C-M: visibly in the form of budgets and other internal monetary devices, such as bonuses and prizes for innovative 'suggestions'; and, perhaps, less visibly in terms of targets, such as nurses reducing 'bed days' for patients (Latimer, 2000) or reductions in 'turnaround days' for customers receiving goods (Munro, 1992). Hence my thinking is that, far from seeking to make spaces of play ostensibly free of 'market logic' - by removing impurities such as what Massumi (1998) calls the 'most vulgar of all, cost' - perhaps creative collaboration might choose - perversely as it sounds - to make the presence of money more explicit? My point is not to amplify the silent injunction to make 'play pay' (Deal \& Kay, 1998). It is rather to suggest that once 'solutions' are broadcast as needing to be arrived at within the ecological press of money, the accounting forms $\mathrm{M}-\mathrm{C}-\mathrm{M}$ takes become part of the problem and are then open to challenge.

\section{Conclusions}

In challenging a managerial view of entrepreneurship, Hjorth (2005) is explicit on how authorised 'spaces of play' may nurture ideas, but says less about how institutions go about increasing entrepreneurial activity in the face of 'market logic' being used to bolster what I have called the 'power of place'. In examining these key cases where forms of reverse-thinking help unleash 'the virtual', and so shaped organisational change over the last century, this paper has sought to open up instead the vexed question of how money, so central to modern formations of 'place', affects these incipient 'spaces of play'. Specifically, in showing how money enters the 'ecological press' of creative endeavour, I detailed complexities of reverse thinking 
that illustrate: 1) the 'automatic' nature money takes on to ensure its circulation; 2) a priority of accounting calculation over science for the entrepreneur; 3 ) the creation of the 'modern manager' by bringing accountabilities in the form of money inside an institution; and 4) the rethinking of the factory towards the customer and away from the tyrant of standard costing.

Contrary to hopes that collaborative creativity will operate under new logics that centre on 'openness, sharing, and external engagement' (Benkler, 2006), it is as likely that any new set of institutional logics will prove to be just as mandatory and exploitative in their own way. As Keijo Rasanen argues about change agents in the introduction to a special issue on 'Making History/Breaking History',

.. [they] have to 'solve the dilemma that the motivational dynamics that are important for a team's commitment to 'making history' in one period may be a restraint on progress in a subsequent period (1991, p.3).

That successful 'reverse thinking' is complex and hard to undertake is because all the elements of formal design 'interact with each other' and typically involve 'contradictory design principles and logics of action' (1991, p.4).

One views with suspicion the idea that, in moving towards a control-centric way of managing, managers ever abandon a 'command' structure. Indeed, in one of my own field studies (Munro, 1991), top management opposed introducing a second strategic value around the notion of 'agility' on the basis it was too open-ended and could not be controlled. Certainly Sloan, in furthering decentralisation, was still adamant the CEO has to retain absolute authority - his own explanation was CEOs just had to 'sell' an innovation instead of imposing it. Hence it is vital to focus not only on how reverse thinking gets deployed as a crucial form in the 'art of tactics' building alliances, understanding the strategy you are up against, and refining argument (Hjorth \& Johannisson, 2008, p.344) - but to explore how combinations of reverse thinking coalesce together and culminate in a reshaping of 'place'.

The apparent turn in institutional logics, away from the slumber of a reliance on routines and repetition (Giddens, 1984) towards incorporating money internally, has deep repercussions going beyond exposing misleading valorisations of 'internal markets'. For those who supported autocracy in the factory also proselytised, as Marx points out, competition as the only co-ordinator of society. And the sting, as Marx (2008, p.219) anticipates in counterpointing the division of labour in society with that of the factory, is that this reliance today on money inducing internal 
competition entails that 'chance and caprice have full play' within institutions as well as without. Indeed, Marx might be less than surprised to find an innovator like Tom Peters (1988, p.xii) justify his managerial revolution - and shedding staff to the bone - with the notion that the 'winners of tomorrow' are those who 'thrive on chaos'?

While a key purpose of this paper is to follow Marx in putting under erasure the term 'the market' as too reified a concept to do the work of co-ordinating society, there is little doubt that the prevalence and persistence of so-called market logics continues to inform many leadership strategies today. In the light of the global chaos in 2008, one might hope nonetheless that work will follow up Zajac and Westphal's (2004) lead in showing equity markets are far from free of institutional logics; and reveal instead how they are ruled by conformity in attitudes and beliefs - a matter tellingly recounted by Lewis (2010). Even if some find the 'vocabularies' (Thornton \& Occasio, 2008, p.121) and manifold devices making money present internally too banal to research, it would be an advance if the over-emphasis given to 'market logics' in recent work on institutional logics was made more nuanced - as, say, forms of rhetoric designed to intimidate as well as exploit. For example, as noted by Latimer and Munro (2015), institutional reform is often preceded by declarations of a financial crisis- a path much copied by Vice Chancellors in the UK as they use 'market logic' to turn our universities into factories. Indeed, it would also be good to see future research on organisation explore the extent to which many senior managers look on crisis (Klein, 2007), as much as competition, as their real ally?

Closer study of the different ways money affects the running of institutions should also provide the depth to day-to-day interaction that Thornton and Occasio (2008) urge for future work on institutional logics. But I hope to have shown how a wider picture is needed. For introducing money to 'make' an internal economy not only incites a 'swarming of incipiencies or tendencies - positively for creativity or negatively as with short-termism. Indeed, rather than shift the logic of exchange from $\mathrm{C}-\mathrm{C}$ towards $\mathrm{C}-\mathrm{M}-\mathrm{C}$ in the name of the market, institutional logics now sediment themselves around money. And, almost inevitably and increasingly, these migrate away from upholding corporate values, like integrity and loyalty, towards deepening the self-justifying orientation of M-C-M. Implicit in Marx's overlooked reversal of earlier logics of exchange to a M-C-M model, discussed earlier, is his brilliant recognition that, in addition to its structuring properties, money has an 'automatic' 
effect on its circulation: namely, that of always demanding to become more! It remains to be seen if this propensity can be harnessed within organisation in ways that incite entrepreneurship? And, critically, without the 'chaos' Marx predicted for society also coming to pervade the internal workings of public institutions and business corporations.

\section{References}

Alles, M., Amershi, A., Datar S., \& Sarkar, R. (2000). Information and Incentive Effects of Inventory in JIT Production. Management Science, 46(12),1528-1544

Anthony, R.N., Dearden, J., \& Vancil, R.F. (1965). Management Control Systems: cases and readings. Homewood, IL: Irwin.

Benkler, Y. (2006). The wealth of networks: how social production transforms markets and freedom. New Haven: Yale University Press.

Beynon, H. (1973). Working for Ford. Harmondsworth: Penguin.

Burawoy, M. (1979). Manufacturing Consent: Changes in the Labour Process under Monopoly Capitalism. Chicago: University of Chicago Press.

Canetti, E. (1973). Crowds and Power, translated by Carol Stewart. New York: Continum.

Chandler, A.D. (1962). Strategy and structure: Chapters in the history of the industrial enterprise. Cambridge: M.I.T. Press.

Chandler, A.D. (1977). The Visible Hand: The Managerial Revolution in American Business. Cambridge, MA: Belknap.

Clegg, S. (1981). Organisation and Control. Administrative Science Quarterly, 26 (4),545-562.

Colebrook, C. (1997). New Literary Histories: New Historicism and Contemporary Criticism. Manchester: Manchester University Press.

de Certeau, M. (1984). The Practice of Everyday Life. Berkeley: University of California Press.

Deal, T., \& Kay, M.K. (1998). Corporate Celebration: Play, Purpose, and Profit at Work. San Francisco: Berrett Koehler.

Dear, A.D. (1988). Working Towards Just-in-Time. Springer.

Deleuze, G. (1988). Bergsonism. New York: Zone. 
DiMaggio, P.J., \& Powell, W.W. (1983). The Iron Cage Revisited: Institutional Isomorphism and Collective Rationality in Organizational Fields, American Sociological Review, 48(2),147-160.

Deming, W.E. (1966). Some Theory of Sampling. Dover Publications.

Derrida, J. (1981). Margins of Philosophy, trans. Alan Bass. Hemel Hempstead: Harvester Wheatsheaf.

Foucault, M. (1970). The Order of Things. London: Tavistock.

Giddens, A. (1984). The Constitution of Society. Cambridge: Polity Press.

Graeber, D. (2011). Debt: The First 5,000 Years. Brooklyn, NY: Melville House.

Gutting, G. (1989). Michel Foucault's Archaeology of Scientific Reason. Cambridge: Cambridge University Press.

Hall, R.W. (1987). Attaining Manufacturing Excellence: Just-in-Time, Total Quality, Total People Involvement. Homewood, Ill.: Dow Jones-Irwin.

Harvey, D. (1989). The Condition of Postmodernity. Oxford: Blackwell.

Hjorth, D. (2005). Organizational Entrepreneurship: with de Certeau on Creating Heterotopias (or spaces for play). Journal of Management Inquiry, 14(4),386-398.

Hjorth, D. (2014). Entrepreneuring as Organisation-creation. In R. Sternberg and G. Kraus (eds) Handbook of Research on Entrepreneurship and Creativity (pp.97-121). Cheltenham: Edward Elgar

Hjorth, D., \& Johannisson, B. (2008). Building new roads for entrepreneurship research to travel by: on the work of William B. Gartner. Small Business Economics, 31(4):341-350.

Hofstede, G. (1968). The Game of Budget Control. London: Tavistock.

Kaplan, R., \& Cooper, R. (1988). Make Cost Right: Make the Right Decisions. Harvard Business Review, September-October.

Klein, J.A. (1990). Revitalizing Manufacturing: text and cases. Richard D. Irwin.

Klein, N. (2007). The Shock Doctrine: The Rise of Disaster Capitalism. Random House.

Kuhn, T. (1970) Scientific Revolutions. Chicago: University of Chicago Press.

Latimer, J. (2000). The Conduct of Care. Oxford: Blackwell.

Latimer, J., \& Munro, R. (2015). Uprooting Class? Culture, world-making and reform. The Sociological Review, 63(2):415-432. 
Latour, B. (1987). Science in Action: How to follow scientists and engineers through society. Milton Keynes: Open University Press.

Lefebvre, H. (1991). The Production of Space. Oxford: Blackwell.

Lewis, M. (2011). The Big Short. New York: W.W. Norton.

Liphschitz, I.N. (1935). The Social Roots of Technical Invention. Journal of the Patent Office Society, 17:927-940.

Mackelprang A.W., \& Nair A. (2010). Relationship between just-in-time manufacturing practices and performance: A meta-analytic investigation, Journal of Operations Management, 28(4),283-302

Malabou, C. (2015). The crowd, translated by Dashiell Wasserman. Oxford Literary Review, 37(1),25-44.

Marx, K. (2008[1887]. Capital (ed. D. McLellan). Oxford: OUP.

Massumi, B. (1998). Sensing the Virtual, Building the Insensible. Architectural Design, 68(5/6),16-24.

Micklethwaite, J., \& Woodridge, A. (1996). The witch doctors: what the management gurus are saying, why it matters and how to make sense of it. London: Heinemann,

Munro, R. (1987). From Just-in-Case to Just-in-Time. The Accountant's Magazine, August,52-54.

Munro, R. (1992). Enabling Participative Change: The impact of a strategic value. International Studies in Management and Organization, 21(4),52-65.

Munro, R. (1995). Managing By Ambiguity: An archaeology of the social in the absence of management accounting. Critical Perspectives on Accounting, 6(4),433-482.

Munro, R. (2001). Calling for Accounts: Numbers, monsters and membership. The Sociological Review, 49(4),473-493.

Munro, R. (2016). Extension and the Disposal of the World: systems, culture, identity and language. The Sociological Review, 64(3),424-446.

O'Toole, J. (1995). Leading change: overcoming the ideology of comfort and the tyranny of custom San Francisco: Jossey-Bass,

Peters, T., \& Waterman, R.H. (1982). In Search of Excellence. New York: Harper \& Row.

Peters, T. (1988). Thriving on Chaos: Handbook for a management revolution. London: Macmillan. 
Powers, T.L., \& Steward, J.L. (2010). Alfred P. Sloan's 1921 repositioning strategy, Journal of Historical Research in Marketing, 2(4),426-442,

Rhodes, M. (1961). An Analysis of Creativity. The Phi Delta Kappan, 42(7),305-310

Rasanen, K. (1991). Making History/Breaking History: the dynamics of organizational transformation. International Studies of Management \& Organization, 21(4),3-8.

Roberts, J. (2004). The Modern Firm: Organisational Design for Performance and Growth. Oxford: Oxford University Press.

Roy, D.F. (1959). Banana Time: Job Satisfaction and Informal Interaction. Human Organization, 18,158-168.

Rosso, B.D. (2014). Creativity and Constraints: Exploring the Role of Constraints in the Creative Processes of Research and Development Teams. Organization Studies, 35(4),551-585.

Schrage, M.D. (2000). The Seriousness of Play. Boston: Harvard Business School Press.

Simmel G. (1997). Metropolis and the City. In D. Frisby and M. Featherstone(eds) Simmel on Culture. London: Sage.

Sloan, A.P., Jr. (1967). My Years With General Motors. London: Pan Books.

Sørensen, B.M. (2012). St Paul's Conversion: The aesthetic organization of labour. Organization Studies, 31(3),307-26.

Sørensen, B.M., \& Spoelestra, S. (2011). Play at Work: continuation, intervention and usurpation. Organization, 19(1),81-97.

Stinchcombe, A.L. (2002). New Sociological Microfoundations for Organizational Theory: A Postscript. In M. Lounsbury and M. Ventresca (Eds.), Social Structures and Organizations Revisited, 19 (pp.415-433). Amsterdam: Elsevier Science.

Thornton, P., \& Ocasio, W. (1999). Institutional Logics and the Historical Contingency of Power in Organizations: Executive Succession in the Higher Education Publishing Industry, 1958-1990. American Journal of Sociology, 105(3),801-843.

Voss, C., \& Clutterbuck, D. (1989). Just-in-Time: A Global Status Report. UK: IFS Publications.

Watkins, E. (1983). Throwaways: Work culture and Consumer education. Stanford: Stanford University Press.

Womack, J.P., Jones, D.T., \& Roos, D. (1990). The Machine That Changed the World: The Story of Lean Production. New York: Rawson Associates. 
Zajac, E.J., \& Westphal, J.D. (2004). The Social Construction of Market Value:

Institutionalization and Learning Perspectives on Stock Market Reactions. American Sociological Review, 69,433-458. 